\title{
The role of BIM in tackling obsolescence, climate change, and sustainability
}

\author{
T. E. Butt ${ }^{1}$, T. J. Francis ${ }^{1}$, D. Greenwood ${ }^{2}$, \\ K. G. Jones ${ }^{3} \&$ A. M. Nasir ${ }^{4}$ \\ ${ }^{I}$ School of Architecture, Built and Natural Environments, \\ Faculty of Architecture, Computing \& Engineering (FACE), \\ University of Wales Trinity Saint David, UK \\ ${ }^{2}$ Department of Mechanical and Construction Engineering, \\ Northumbria University, UK \\ ${ }^{3}$ Department of Engineering and the Built Environment, \\ Anglia Ruskin University, UK \\ ${ }^{4}$ Safe Australia Consulting Engineers, Australia
}

\begin{abstract}
Although the BIM technology is applicable to both new and existing buildings, it is arguably more established in the former than the latter. This is despite the fact that, in the UK alone, $70-80 \%$ of what has been built by 2010 , is estimated to continue to exist for a number of decades to come: including the years 2020 and 2050 (the two main temporal deadlines in the Climate Change Act, 2008). In addition, this existing building stock is subject to obsolescence (both climate change-induced and non-climate change-associated) which in turn compromises sustainability. Thus, there are three notions that appear to be interwoven, i.e. Obsolescence, Climate Change, and Sustainability: the question is whether BIM can be exploited to address these.

There has been only limited research work to explore the possible influence of BIM upon obsolescence, climate change, and sustainability as individual issues, and none reported, to-date, in terms of an approach to their collective consideration. This paper conceptually explores how BIM can be related with all three crucial notions simultaneously as well as discretely. It is argued that such studies can be particularly valuable in the face of escalating pressures in terms of future obsolescence risks, overwhelming evidence of climate change, and escalating sustainability agendas. The paper reviews current work that relates
\end{abstract}


state-of-the-art BIM to the three notions, both separately and collectively, and thereby delineates the potential for BIM to play a role in addressing the three issues simultaneously.

Keywords: BIM, obsolescence, sustainability, climate change, sustainable development, built environment.

\section{Introduction}

\subsection{Background}

Whatever is human-made, tends to become obsolete over time due to physical factors such as chemical degradation and physical damage. However, the process of obsolescence is not limited to material and physical factors. Social, cultural, technological and political factors (such as technology innovation, variation in customer demands, change in legislation, social pressures, advancement of knowledge, currency inflation; civil unrest or conflict of interests) can also drive obsolescence. Moreover, climate change is another and newest element to act as an additional driver of obsolescence in a number of ways - both directly and indirectly. Thus, some of the factors causing obsolescence are climate changerelated while others are not.

However, published and anecdotal evidence in the built environment suggests that not only the term obsolescence is not common, but also that its nature as a multi-dimensional and growing concept is seldom fully appreciated with its wide range of implications [1]. Some implications are conventional: that is, in terms of the degradation of a component of a system that renders the component obsolescent. This we refer to as 'internal' obsolescence. But new 'external' factors such as how climate change and new environmental legislation are inducing obsolescence risks to various systems of the existing built environment are not sufficiently considered. Generally, it does not appear to be recognised that increase in the requirement of adaptation, repair, overhauling, retrofitting, or refurbishment of a system is a direct indicator of an increase in obsolescence.

Apart from the obsolescence and climate change in their individual right, the third aspect is that of sustainability. Obsolescence and sustainability are inversely related. The more the obsolescence in a system or component the more the 'unsustainability' and vice versa. This is true overall as well along each of the three principal dimensions of the sustainability development philosophy [2]. More details are provided in Section 3.

In the literature to date, no evidence has been found of consideration of the three aspects (i.e. obsolescence, sustainability and climate change) together. Equally, there no study has so far been carried out which focuses on how the rapidly-evolving BIM technology has or can accommodate all three aspects. The hypothesis is that the BIM technology is more focused on 'internal' rather than 'external' obsolescence. Thus, climate change, which is predominantly an external obsolescence, is not yet catered for in BIM technology. In addition, sustainability is not deemed as opposite of obsolescence in the technology, at least not consciously. In summary, there is no consideration of how BIM technology can 
inform and/or be informed by the three different themes (obsolescence, sustainability, and climate change) and their relationship with one another.

\subsection{Aims, objectives and research methodology}

The paper aims to establish the state-of-the-art in relation to obsolescence, sustainability and climate change, thereby pave a path for further research that may lead to render the fast developing BIM technology more diverse and yet holistic and integrated. In order to achieve this aim, the main objectives are:

1. Identify main obsolescence types and implications;

2. Establish the relationship between obsolescence and climate change;

3. Describe the relationship between obsolescence and sustainability;

4. Explore the state-of-the-art of BIM technology; and

5. Delineate the relationship of the three notions (in 1,2 and 3 above) with BIM technology.

\section{Obsolescence versus climate change}

There is a wide range of types, aspects and implications of obsolescence. A few main types are listed below with a systematic categorisation to explain various facets and implications of obsolescence, including the crucial factor of climate change.

\subsection{Financial and functional obsolescence}

Irrespective of causes, financial obsolescence means loss in value whereas functional obsolescence is loss of usefulness, effectiveness, efficiency or productivity. Financial obsolescence is also termed as social or economic obsolescence (depending on the driving cause), and functional obsolescence as technical obsolescence. [1]. Sometimes a whole system may become functionally obsolete, although mostly obsolescence involves embedded parts of a complex system where the design life of the system typically exceeds 20 years [3]. This obsolescence in part, if not fully, is generally due to technological advancements of embedded parts of a complex system and has even been referred to as the 'dark side' of innovation [4]. Functional obsolescence is a major parameter affecting technical installations and influences the value of an office building [5]. Another scenario is that of a building that might be structurally fine but unable to generate enough income to keep it running in its present state. This can be referred to as a case of financial obsolescence [6]. On the other hand, it would be a matter of functional obsolescence if the same building cannot perform to the required level due to some structural defect appearing in the building e.g. precipitation leaking through the roof.

\subsection{Internal and external obsolescence}

Irrespective of whether obsolescence is in value or function or both, internal obsolescence in a component or built asset is due to factors that exist within the 
component or built asset. Factors could include: general wear and tear, fatigue, corrosion, oxidation, evaporation, rusting, leaking of gas/water or any other fluid like coolant, breaking, breakdown/failure, age, and so on.

External obsolescence is temporary or permanent impairment in value or usefulness of a built asset due to factors outside the system. Factors that could derive external obsolescence either individually or in various combinations include: climate change; changes in existing or advent of a new environmental legislation; social forces/pressure groups; arrival of new technologies; technological innovation; knowledge advancement; labour market and unemployability (e.g. specific skill set not available); inflation of currency; rise in interest rate; rise in fuel and/or energy prices; fluctuation in demand, supply, inventory, etc.

In summary, external obsolescence could be due to any external factor - from a large employer in the area shutting its doors to a zoning change, through a property located under an airport flight pattern, to even a house in one's neighbourhood that seems to attract broken down cars. However, boundaries between internal and external factors of obsolescence for a given setting may not necessarily always be physical, they can also be virtual [1].

\subsection{Obsolescence and climate change}

Irrespective of whether obsolescence is internal or external and financial or functional, if a given obsolescence is due to impacts of climate change it is referred to by the authors as Climate Change Induced Obsolescence, as opposed to NonClimate Change Induced Obsolescence. Furthermore, climate change associated obsolescence can be directly or indirectly-induced as described below:

\subsubsection{Directly induced climate change obsolescence}

Obsolescence that is caused by direct influence of climate change factors is termed as directly induced climate change obsolescence. For instance:

- Due to water level rise in water bodies as a result of climate change, estimated flood levels are higher than before. This implies that current level of electrical cables, power points, and appliances from the ground in a given built environment may not be high enough any longer to defend against flooding should it happen. This is direct induction of climate change associated obsolescence in the flood defence mechanism.

- As a result of climate change impacts, rainfall is on the increase in both frequency and intensity. In many cities combined sewer systems were not designed to cope with this. Thus, pluvial flood events are happening more frequently, which is an indicator of increase in the directly induced climate change obsolescence in existing combined sewers. To overcome this increasing obsolescence risk, as an adaptation measure, the 'grey' infrastructure needs to be replaced by 'blue' and 'green' infrastructure as appropriate: an example of this being the concept of Water-Sensitive Urban Design (WSUD) $[7,8]$. 


\subsubsection{Indirectly induced climate change obsolescence}

Obsolescence that results from climate change factors in an indirect manner is referred to as indirectly induced climate change obsolescence. For example:

- Introduction and application of clean energy technologies is on the increase. The cost of these substitutes is presumed to decrease with cumulative use because of learning-by-doing and widening of the use like it happened with e.g. computers. In some cases these clean technologies are being adopted voluntarily and in others due to mandatory factors like carbon cap, carbon tax, and cap-and-trade regarding control on aggregate emissions from a fossil fuel (e.g. coal). In both the categories, climate change is a fundamental and original driver either wholly or partly. This can be deemed as indirectly climate change induced obsolescence that has started to happen at various levels in a number of aspects of industrial economies, buildings, and our life styles in general - which are currently predominantly based on fossil fuels one way or another as a matter of 'carbon lock-in' [9-11].

\section{Obsolescence versus sustainability}

Any constituent of the built environment (such as a building or infrastructure) grows to become obsolete or suffers increasing obsolescence over time. Moreover, what has been and is being built now will predominantly be around as a substantial part of our built environment for decades to come, and is, therefore, bound to suffer various degrees of obsolescence in different ways. In order to render our built environment more sustainable, obsolescence needs to be addressed, either in new construction or in remediating the existing built environment. There is a large number of factors which play a role, either alone or collectively, in causing obsolescence. Examples of these factors are not only conventional ones such as wear and tear and aging, but also contemporary ones that include energy consumption efficiency, environmental pressures such as reduction of carbon dioxide (also referred to as carbon emissions) and other greenhouse gas emissions, change or arrival of new legislation or regulations, change of use, clean and waste water management, water quality and resources, land use, land contamination and soil quality, air emissions, changing occupier or end user demands, waste management, ecological concerns and health and safety.

The afore-listed contemporary factors also form part of considerations of the sustainable development or sustainability philosophy in one way or another. As evidence it can be seen that all such factors (directly or indirectly) constitute National Sustainability Strategy and Headline Indicators of Sustainable Development in the UK as a whole, and also at the constituent country level, for example, Welsh and Scottish Headline Indicators [12-17]. Hence, there is a strong link between obsolescence and sustainability.

The afore-listed contemporary factors which cause obsolescence are also the ones which cause 'unsustainability' for the built environment [2]. These factors need to be controlled in order to render a given built environment sustainable. Figure 1 conceptually illustrates the links between sustainable development 
philosophy, the built environment, obsolescence, and drivers such as climate change. For a number of illustrative and real-world examples the readers are referred to Butt et al. [2] publication.

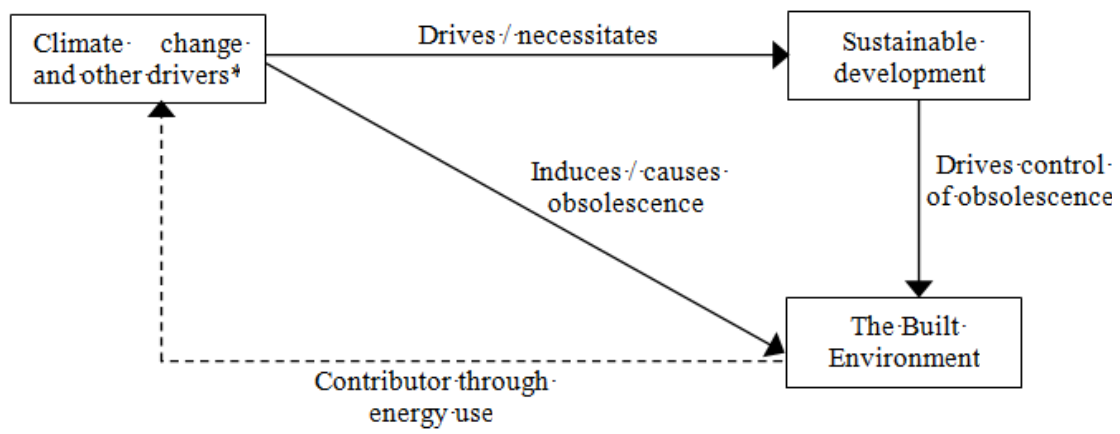

Figure 1: Links between sustainability, the built environment, obsolescence, and their drivers [2]. *Other drivers for sustainable development include resource availability, intergenerational equity, social inclusion, economic factors (like inflation), and environmental legislation.

\section{BIM versus obsolescence, sustainability and climate change}

\subsection{What is BIM?}

BIM (an abbreviation of Building Information Modelling) is relatively new and ever-growing technology with many definitions. In simple terms, it is a means by which a building can be understood through the use of a digital model. BIM brings together in one place information about the components of a building and enables access of that information for various purposes, e.g. to integrate different aspects of the design more effectively. The word 'Building' in the title may be misleading for some. BIM is just as relevant to the civil engineering sector and other stakeholders (Figure 2) [18-20].

In the life-cycle context (Figure 3), BIM can be defined as a digital representation of physical and functional characteristics of a facility and a shared knowledge resource for information about a facility forming a reliable basis for decisions during its life-cycle - spanning from earliest conception to demolition [18].

In terms of time, there are two main categories that the built environment can be divided into i.e. existing buildings and new buildings. While BIM processes are established for new buildings, the majority of existing buildings are not maintained, refurbished or deconstructed with BIM yet. One obvious reason for this is that BIM is relatively easier to apply to a new building as the two can be married together from the outset, whereas existing buildings are a very different 


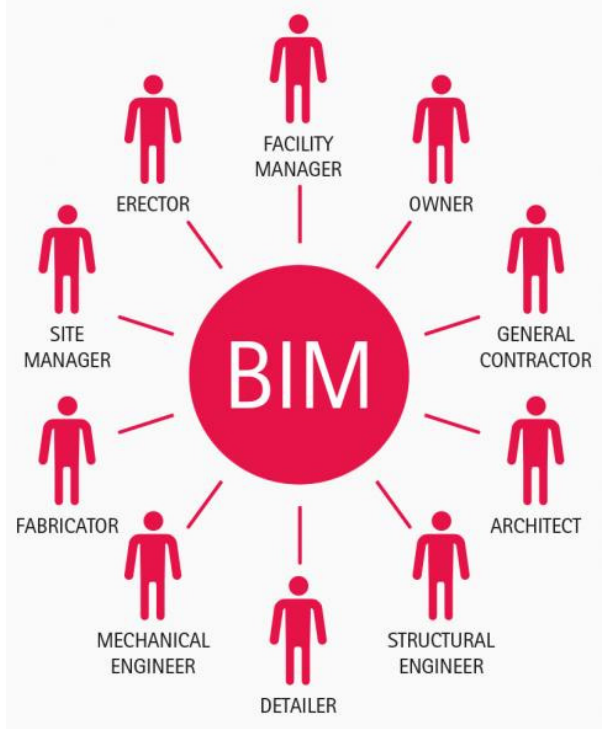

Figure 2: Diverse stakeholders in a building construction [31].

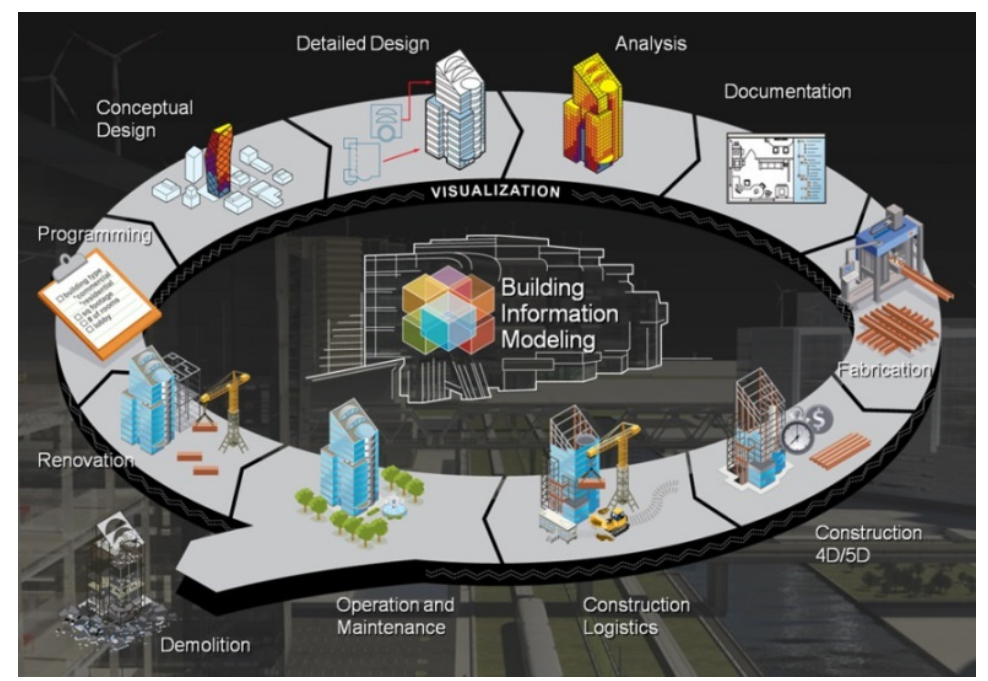

Figure 3: Stages of a building in its life cycle [32].

proposition, and there are a number of challenges in trying to model an existing building $[21,22]$. On the other hand, the biggest challenge of all is that about 70 $80 \%$ of what has been built in the UK already by 2010 , is to continue to stand for many decades to come [23-25]. Thus, in the context of these buildings and assets, BIM technology has to be adopted retrospectively. 


\subsection{Obsolescence, sustainability and climate change: all three together versus BIM}

After describing the three notions individually and in connection to each other, these are now discussed in connection to BIM technology. From the anecdotes of experts in the industry and the review of the literature to date [e.g. 26-30], there has been found little evidence that BIM clearly and directly caters for obsolescence as such. For example, Figure 2 illustrates a diverse range of stakeholders but does not pay attention to experts in obsolescence or even those in climate change and sustainability. Figure 1 is, however, a part of the lifecycle of a building - the construction stage. Figure 3 describes the lifecycle of a building. Even in this case, there is no direct consideration of obsolescence or even climate change and sustainability.

However, in an indirect way obsolescence is considered in the lifecycle of a building but only during its maintenance or refurbishment. They come into play after a building has been constructed and the end-user has started to use it. That is, once a building undergoes its operational stage, it starts to lose its performance over time. Thus, after certain period of time maintenance has to be carried out to bring its performance back to its original design performance. This way, there could be a number of maintenance cycles (full or in part) before the original design level performance of the building ceases to sufficiently meet the demands of the end-user. At this point in the life of the building, refurbishment is carried out to enhance the performance level of the building above and beyond its original design level. This way a number of maintenance and refurbishment cycles may be applied in the lifetime of the building before it is not viable to continue and the building is either rendered derelict or demolished, eventually to be replaced by a new development.

In summary, it is the maintenance and refurbishment (cycles) which keep combating the obsolescence of a building. However, this obsolescence is generally due to the conventional reasons of obsolescence - the internal obsolescence. In this context, the 'unsustainability' element of a given building is automatically addressed, for obsolescence and sustainability are inversely related (Section 3.2). However, when it comes down to external obsolescence which occurs due to external factors such as climate change (be it directly induced or indirectly induced - Section 2.2.3), BIM is has not yet been found developed enough to cater for this.

\section{Concluding remarks}

This paper has presented innovative insights around BIM in relation to obsolescence, sustainability and climate change. The paper does this in a systematic manner by first exploring domains of obsolescence, sustainability and climate, each separately, and then together along with characteristics of BIM.

Specifically, in connection to obsolescence, areas that are briefly, partly and above all less consciously addressed by the technology are described i.e. maintenance and refurbishment to overcome internal obsolescence due to 
conventional factors such as wear and tear. Then the paper has identified those areas which the technology yet needs to grow into to become more diverse, holistic and integrated i.e. accommodate external obsolescence factors such as climate change to enhance the degree of sustainability of the built assets even more.

The main issue is that we are to live with $70-80 \%$ of our already built environments (buildings and infrastructures) for many decades to come. However, these exiting build assets are facing obsolescence risk (thereby jeopardizing their sustainability) due to contemporary factors such as climate change. On the other hand, the investment in these existing built assets was estimated at approximately $£ 129$ billion in 2007 in the UK alone [33]. Thus, in order to protect investment into these existing built assets, actions are needed to be taken now. One potentially affective way can be to enhance the use of BIM to become more holistic and integrated - so that the focus is not only internal obsolescence but also external obsolescence due to climate change. Thus, BIM is yet to develop substantially beyond its current state-of-the-art to accommodate obsolescence, sustainability and climate change with diverse range of direct and indirect as well as internal and external implications, some of which have been briefly captured in this paper.

\section{References}

[1] Butt, T. E.; Camilleri, M.; Paul, P. and Jones, K. G. 2015, 'Obsolescence Types and the Built Environment - Definitions and Implications', International Journal of Environment and Sustainable Development (IJESD), Vol. 14, No. 1, pp. 20-39.

[2] Butt, T. E.; Heywood, C.; Paul, P. and Jones, K. G. 2014, 'Sustainability of and Obsolescence in the Built Environment - The two contrary notions', Sustainability - The Journal of Record, Vol. 7, No. 2, pp. 116-122.

[3] Kumar, U. D. and Saranga, H. 2010, 'Optimal selection of obsolescence mitigation strategies using a restless bandit model', European Journal of Operational Research, Vol. 200, pp. 170-180.

[4] Gravier, M. J. and Swartz, S. M. 2009, 'The dark side of innovation: Exploring obsolescence and supply chain evolution for sustainmentdominated systems', Journal of High Technology Management Research, Vol. 20, pp. 87-102.

[5] Allehaux D. and Tessier P. 2002, 'Evaluation of the functional obsolescence of building services in European office buildings', Energy and Buildings, Vol. 34, No. 2, pp. 127-133.

[6] Nwoko, A. 2010, The nature of obsolescence, Ezine@Articles, 09 February. ezineatricles.com/?The-Nature-of-Obsolescence\&id=3714148, Real Estate: Property Management, Downloaded: 13 April 2013.

[7] Ashley, R; Lundy, L.; Ward, S.; Shaffer, P.; Walker, L.; Morgan, C.; Wong, T. and Moore, S. 2013, 'Water-sensitive urban design: opportunities for the UK', Municipal Engineer, Volume 166, Issue ME2, pp. 65-76.

[8] Stride, P. (March) 2013, Thames Tideway Tunnel Debate: Is a mixed solution the answer? - Future proofing London. The Environment Magazine 
(formerly WEM), CIWEM (Chartered Institution of Water and Environmental Management), pp. 18-19.

[9] Ji, G.; Gunasekaran, A. and Yang, G. 2014, 'Constructing sustainable supply chain under double environmental medium regulations', International Journal of Production Economics, Vol. 147, Part B, pp. 211 219.

[10] Chakravorty, U.; Leach, A. and Moreaux, M. 2012, 'Cycles in nonrenewable resource prices with pollution and learning-by-doing', Journal of Economic Dynamics \& Control, Vol. 36, Issue 10, pp. 1448-1461.

[11] Unruh, G. C. 2008, 'Understanding carbon lock-in', Energy Policy, Vol. 28, pp. 87-830.

[12] DEFRA (Department for Environment, Food and Rural Affairs), 2009, Sustainable development indicators in your pocket 2009, An update of the UK Government Strategy indicators, Crown Copyright.

[13] Munday, Max and Roberts, Annette. (July) 2006, Developing Approaches to Measuring and Monitoring Sustainable Development in Wales: A Review, Regional Studies, Vol. 40.5, pp. 535-554.

[14] Al Waer, H. and Sibley, M., 2005, Sustainability Indicators: Complexity of measurements and new trends, 11th Annual International Sustainable Development Research Conference, Helsinki, Finland, 6-8 June.

[15] London SDC (London Sustainable Development Commission), (May) 2005, London Sustainable Development Commission, 2005 report on London's Quality of Life indicators, Greater London Authority.

[16] Plows, A. J.; Jones, J. M.; Foley, S. A.; Butt, T. E.; and Pomeroy, I. R. 2003, 'Awareness of Best Practice for Sustainable Development: The feasibility and use of a broad-based sustainability tool by organisations in Wales', The 2003 Int. Sustainable Development Research Conference, Nottingham, UK, 24-25 March, pp. 353-361.

[17] Scottish Parliament (The Information Centre-SPCI). (May 7) 2002, Sustainable Development (Updated), SPCI Briefing 02/47. Scottish Parliament.

[18] WSP (William Sale Partnership) Global Group Inc. 2015, What is BIM? http://www.wspgroup.com/en/who-we-are/in-the-media/news/2013/whatis-bim/ (Downloaded: 25 May 2015), WSP.

[19] NBS (National Building Specification - owned by RIBA Enterprises Ltd), (Downloaded: 25 May) 2015, Building Information Modelling, http://www.thenbs.com/bim/what-is-bim.asp, NBS/RIBA.

[20] Tekla Corporation, 2015a, What is BIM? http://www.tekla.com/company/ building-construction/what-is-bim, Downloaded: 25 May 2015, Tekla Corporation.

[21] Volk, Rebekka; Stengel, Julian and Schultmann, Frank. (March) 2014, Building Information Modeling (BIM) for existing buildings - Literature review and future needs, Automation in Construction, Vol. 38, pp. 109-127.

[22] Klaschka, Robert. (17 October) 2013, Making BIM work for existing buildings, http:/www.building.co.uk/making-bim-work-for-existingbuildings/5061935.article, Downloaded 29 May 2015. 
[23] Butt, T. E.; Jones, K. G.; Savić, D. A.; Gorse, C. A.; Paul, P.; Hudson, J. P. (Accepted: October) 2013, Built Environments and 'Direct' Energy Consumption - A conceptual methodology framework to facilitate delivery of the Climate Change Act 2008, Environmental Engineering and Management (EEM) journal.

[24] Butt, T. E.; Giddings, B.; Cooper, J. C.; UMEADI, B. B. N. and Jones, K. G. 2010a, 'Advent of Climate Change and Energy Related Obsolescence in the Built Environment', 16th Int. Conference on Sustainability in Energy and Buildings, Brighton, UK, 5-7 May.

[25] Butt, T. E.; UMEADI, B. B. N. and Jones, K. G. 2010b, 'Sustainable Development and Climate Change Induced Obsolescence in the Built Environment', International Sustainable Development Research Conference, Hong Kong, China, 30 May-1 June.

[26] Irizarry, Javier; Karan, Ebrahim P. and Jalaei, Farzad. 2013, Integrating BIM and GIS to improve the visual monitoring of construction supply chain management, Automation in Construction, Vol. 31, pp. 241-254.

[27] HM Government, 2012, Building Information Modelling - Industrial strategy: government and industry in partnership, URN 12/1327, Crown Copyright.

[28] Dell and BD+C (Building Design + Construction), (March 15) 2011, Future-Proofing BIM - A white paper presented by Dell and $\mathrm{BD}+\mathrm{C}$, https://www.wbdg.org/pdfs/1103_dell_bdc_whitepaper.pdf, Dell and $\mathrm{BD}+\mathrm{C}$.

[29] Sheth, A.Z., Price, A.D.F. and Glass, J., 2010, BIM and refurbishment of existing healthcare facilities. IN: Egbu, C (ed.). Proceedings of the 26th Annual ARCOM Conference, 6-8 September, Leeds, United Kingdom, vol. 2, pp. 1497-1506. Loughborough University Institutional Repository.

[30] Tuohy, Paul. 2009, Simulation and BIM for building design, commissioning and operation: A comparison with the microelectronics industry, Eleventh International IBPSA Conference - Building Simulation 2009, pp. 15381545, July 27-30, Glasgow, Scotland, UK.

[31] Tekla Corporation, 2015b, Tekla Promotes Open Approach to BIM, http://www.tekla.com/company/building-construction/Open-BIM, Downloaded: 25 May 2015, Tekla Corporation.

[32] Dispenza, Kristin, (June 29) 2010, The Daily Life of Building Information Modeling (BIM), http://buildipedia.com/aec-pros/design-news/the-dailylife-of-building-information-modeling-bim, Downloaded: 29 May 2015, Buildipedia.com.

[33] UK Status online. 2007, Gross Fixed Capital Formation at Chained Volume Measure. 